\title{
Abdominal implantation of intraocular lenses resulting in the formation of reactive membranes*
}

\author{
J. Reimer Wolter ${ }^{1 * *}$ and Steven L. Kunkel ${ }^{2}$ \\ Departments of ${ }^{1}$ Ophthalmology and ${ }^{2}$ Pathology, University of Michigan Medical Center, Ann Arbor, Michigan 4819, USA
}

\begin{abstract}
For a better understanding of the cytological principles involved in the formation of reactive membranes on lens implants in the human eye, two kinds of modern implants were placed into the peritoneal space of mice. Continous membranes mainly composed of macrophages were observed after 5 days. The membrane on a polymethylmethacrylate implant contained numerous large giant cells, while there were no giant cells on a glass implant. Implantation of intraocular lenses into the abdomen of mice is suggested as an excellent testing situation for implants of different composition and shape.
\end{abstract}

\section{Introduction}

Peritoneal macrophages of the mouse have been used successfully in tissue culture expermients to demonstrate the affinity of these macrophages to intraoccular lens implants and to observe the formation of separating membranes on their surface [7] and other experimental results by Wolter and Kunkel, submitted for publication. These membranes were composed of an eosinophilic capsule-like acellular portion and a cellular part composed of reactive macrophages. Close resemblances were found between these reactive membranes of mouse-macrophage origin and the early stages of membranes found on lens implants removed from human eyes within a few months of implantation [4]. The first attempts of an adjustment of the mouse macrophages to a more permanent situation were seen. However, the time limits of the tissue culture experiments did not allow for the full development of the later stages of the cells, resulting in the formation of the typical pattern of epithelioid, fibroblast-like, and giant cells of different types, in association with the acellular capsule known from the study of implants removed after longer periods in the human eye $[1,2,6]$.

For a better experimental demonstration of the later stages of cells of macrophage origin on the surface of ocular lens implants, it was thus decided to place these implants into the abdominal space of living mice. Under these conditions they could have the continuing exposure to plentiful and continuously reproducing peritoneal mouse macrophages under more "normal" conditions and for a longer time.

\footnotetext{
*Supported by The Research to Prevent Blindness Inc., New York, N.Y.

** Offprint requests to: J. Reimer Wolter, M.D.
}

\section{Experiments}

The peritoneal space of two mice was opened under general anesthesia and sterile conditions. The sterilized optical portion of a polymethylmethacrylate intraocular lens implant was placed into the abdomen of one mouse and that of a glass implant into the abdomen of the other. The abdominal wound was immediately closed with clips. The mice survived the operation without difficulty and did not show any signs of discomfort or disease. They were killed after 5 days. When the peritoneum was opened at the end of this period, the implants were found to be freely movable and without adhesions in the abdominal space. The adjacent peritoneum did not appear red, irritated, or scarred. The removed implants exhibited a grossly visible white capsule. Upon their removal, the implants were immediately fixed in 10\% buffered formalin for at least $2 \mathrm{~h}$. The lens implant cytology technique [3] was used to stain the implants with hematoxylin and eosin.

\section{Cytological description}

The polymethylmethacrylate lens implant was covered with a continuous monolayer of densely arranged cells (Fig. 1). Small patches of thicker layers of cells and a bandlike formation of a dense superficial accumulation of cells were found in addition to the continuous monolayer (Fig. 1). All the cells were quite firmly attached to the plastic surface. A few artificial interruptions were seen in places, where the lens had been grasped with forceps during its removal from the mouse abdomen before fixation (Figs. 1-3). Most of the cells in this layer were mononuclear macrophages, but quite a few polymorphnuclear leukocytes (PMNs) were mixed in. Many of the macrophages had developed a more extensive protoplasm and a slightly larger round or oval nucleus - as compared to the usual free-moving mouse macrophages - and thus resembled so-called epithelioid cells. In areas with relatively few cells on the implant surface, some macrophages had started to form protoplasmic processes, resulting in the star-shaped or bipolar cell forms that have been called fibroblastlike cells on lens implants (Fig. 7).

Great numbers of large giant cells, with a ringlike arrangement of their nuclei in the midperiphery of their generally clear protoplasm were the outstanding feature of the

\footnotetext{
1 This is to thank IOLAB corporation of Covina, California, and Lynell Medical Technology Inc. of New York, N.Y., for supplying the lens implants used for this study
} 


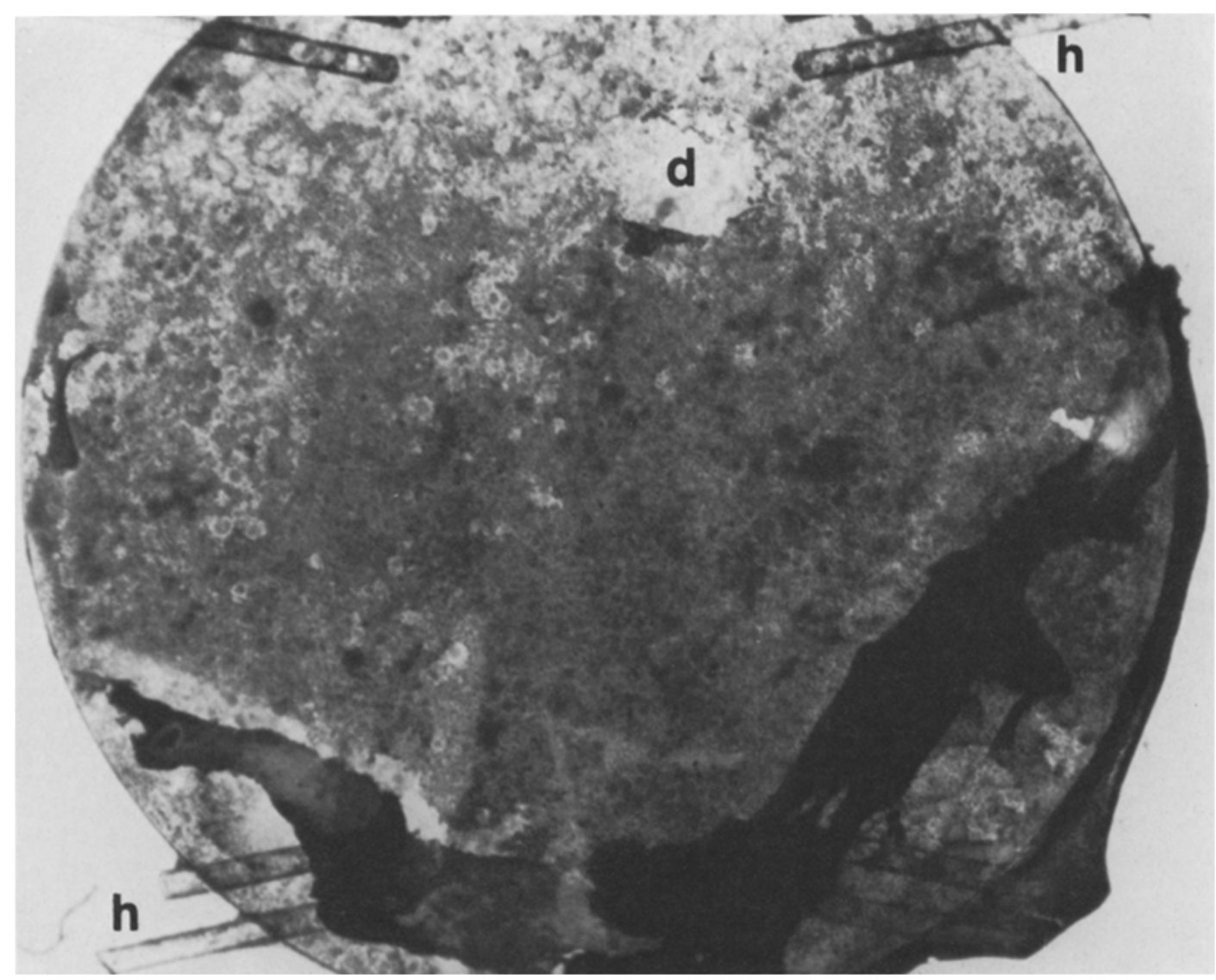

Fig. 1. View of the whole optics of the polymethyl-methacrylate (plastic) implant, after 5 days in the peritoneal space of a mouse, and covered with a dense cellular membrane. The insertions of haptics $(h)$ and a defect in the membrane on the surface $(d)$ are seen. The inferior part of the lens exhibits a bandlike condensation of cells. Lens implant cytology technique, H \& E stain, photomicrograph $\times 25$

cell membrane on the plastic implant (Figs. 3-6). These giant cells were not all of equal size. The largest ones contained up to about 80 nuclei and some of them contained mononuclear cells within their protoplasm (Fig. 6). Different stages in the development of these giant cells on the implant could be observed. This started out with the accumulation of a group of single macrophages. These arranged themselves in a circle and fusion of the protoplasm of these cells in their ringlike arrangement started in the center. No mitoses were observed in the cells that formed the giant cells. In their fully developed form these giant cells had an almost perfect ringlike arrangement of their nuclei, an eosinophilic central protoplasm, and a virtually unstained halolike periperal zone (Fig. 6).

The piece of peritoneum removed from the aera, where the implant was found in the abdomen of the mouse with the plastic implant, was entirely normal and did not exhibit accumulation of inflammatory cells or other obvious signs of irritation.

The glass lens implant was also left in the abdomen of a mouse for 5 days. When the mouse was killed and the abdomen opened, the glass implant was found freely movable under the liver and did not have adhesions to the peritoneal surface. Implant cytology study after formalin fixation revealed a distinctly more massive accumulation of macrophages all over the glass implant and its plastic rim (Figs. 8 and 9), as compared to that found under parallel conditions in the mouse with the plastic implant. On the glass implant massive macrophages had formed more than one layer of cells, and these were very densely arranged (Fig. 10) and had firm connections to the glass surface. Fewer PMNs were seen in comparison to the plastic implant and there were no giant cells found. Only very occasionally were there single macrophages with an enlarged nucleus and more extensive protoplasm (Fig. 10). The layer of macrophages on the plastic rim of the glass implant was not as thick as that on its glass optics (Fig. 9). However, the macrophages had found entry to the narrow spaces between the glass optics and the plastic rim and settled there (Fig. 9).

\section{Discussion}

The present experiment can serve as a prototype for a testing situation that many well have a promising future in the study of the basic reactive changes on the surface of lens implants. In its first application, this technique already supports the earlier observations made by exposing intraocular lens implants to peritoneal mouse macrophages under tissue culture conditions [7] and other findings (submitted for publication) by Wolter and Kunkel: These earlier experiments revealed a great affinity of the macrophages to the surface of the implants. In the presence of great numbers of macrophages, these have become firmly adherent to the lens implants and have formed a densely cellular monolayer covering all of their surface [7]. Differentiation of the macrophages into epitheloid cells, fibroblastlike cells, and mul- 


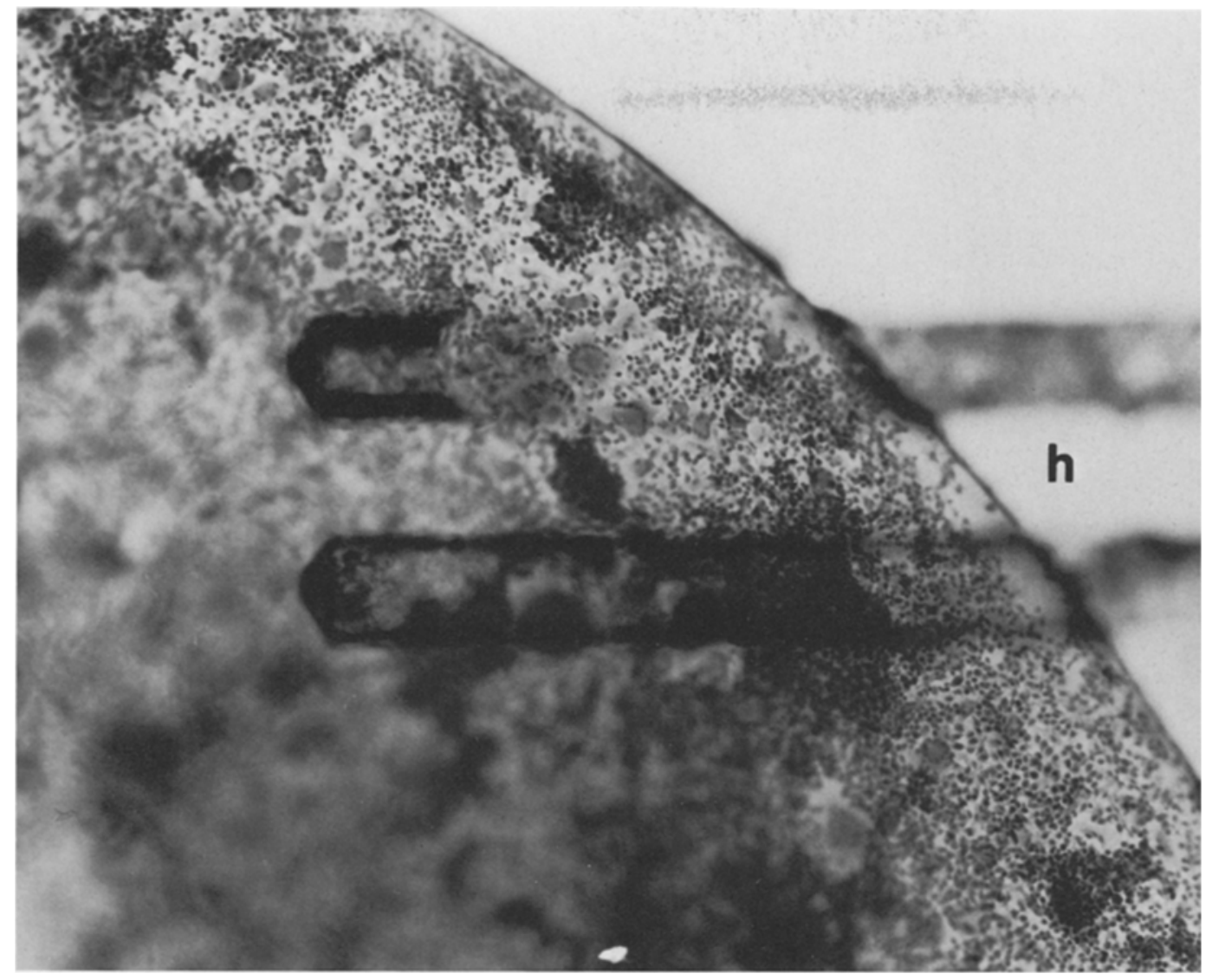

Fig. 2. Portion of the edge of the plastic implant with insertion of haptics $(h)$. The dense monolayer of macrophages with occasional patches of thicker accumulations of cells are seen. Lens implant cytology technique, H \& E stain, photomicrograph $\times 90$

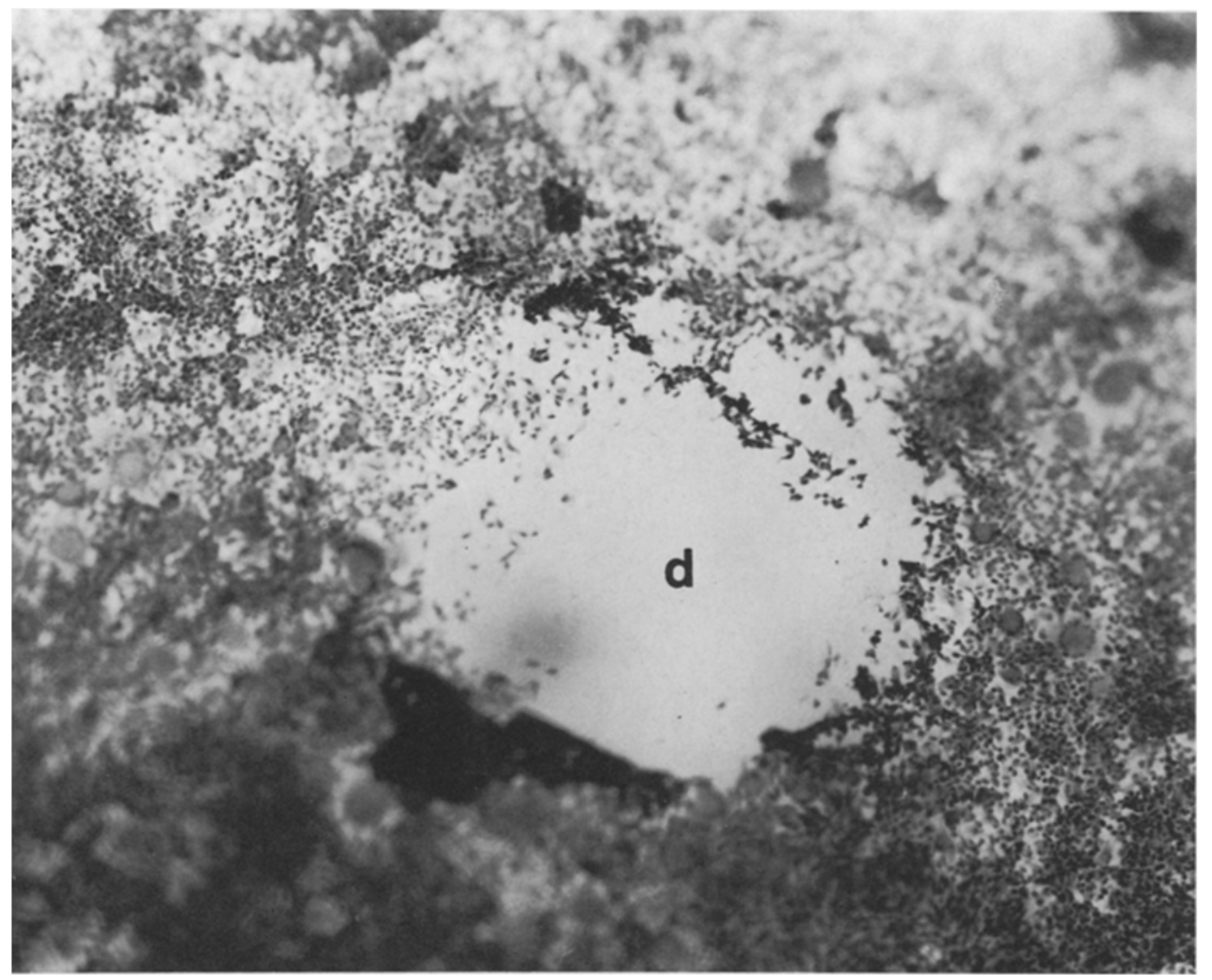

Fig. 3. The defect $(d)$ in cell layer of the front surface of the plastic implant. Occasional giant cells can be recognized. Lens implant cytology technique, $\mathrm{H} \& \mathrm{E}$ stain, photomicrograph $\times 90$ 


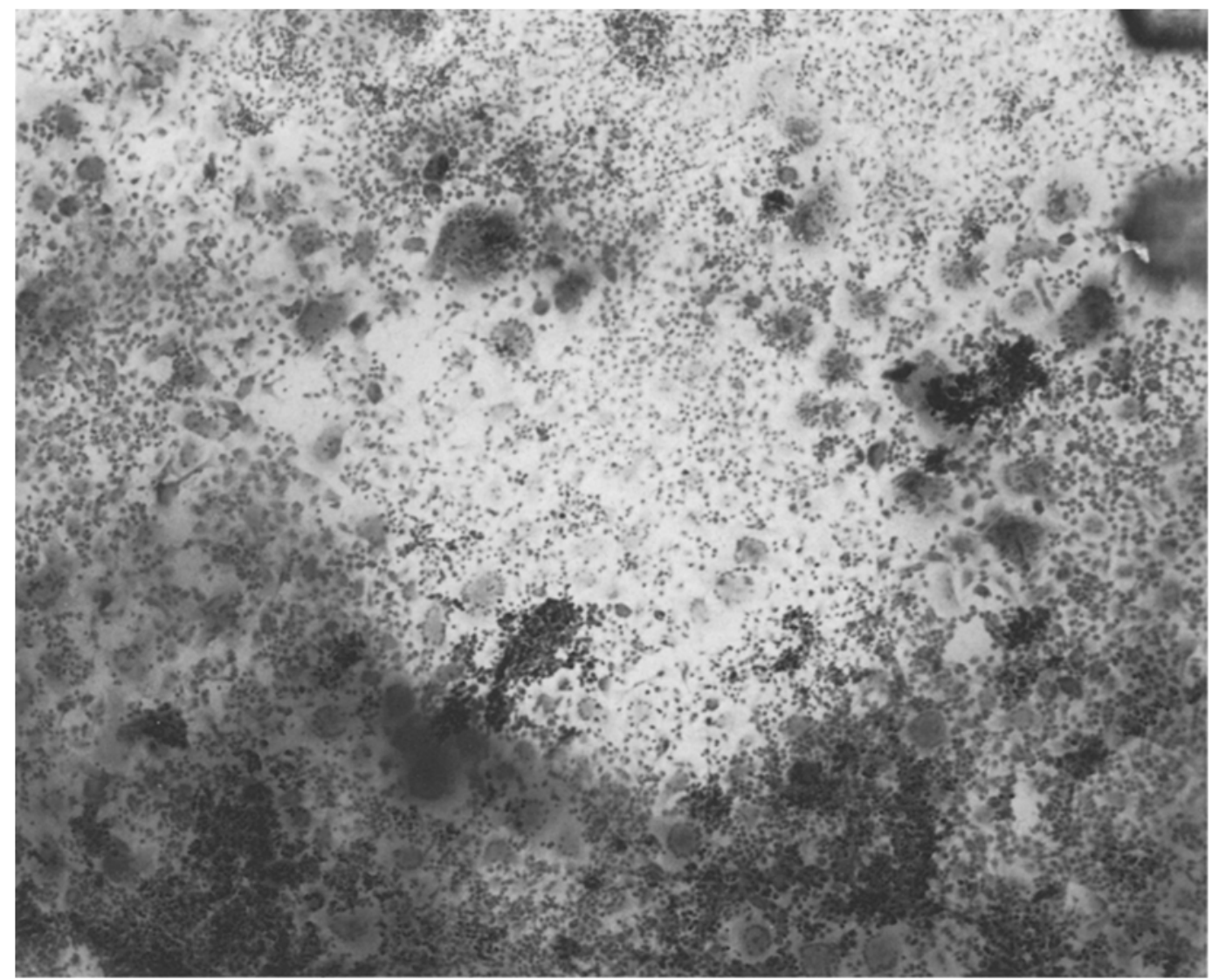

Fig. 4. Focusing on the back surface in the region of the defect $(d)$ seen in Fig. 3 shows the monolayer of macrophages on the back surface of the plastic implant with many giant cells. Lens implant cytology technique, $\mathrm{H} \& \mathrm{E}$ stain, photomicrograph $\times 90$

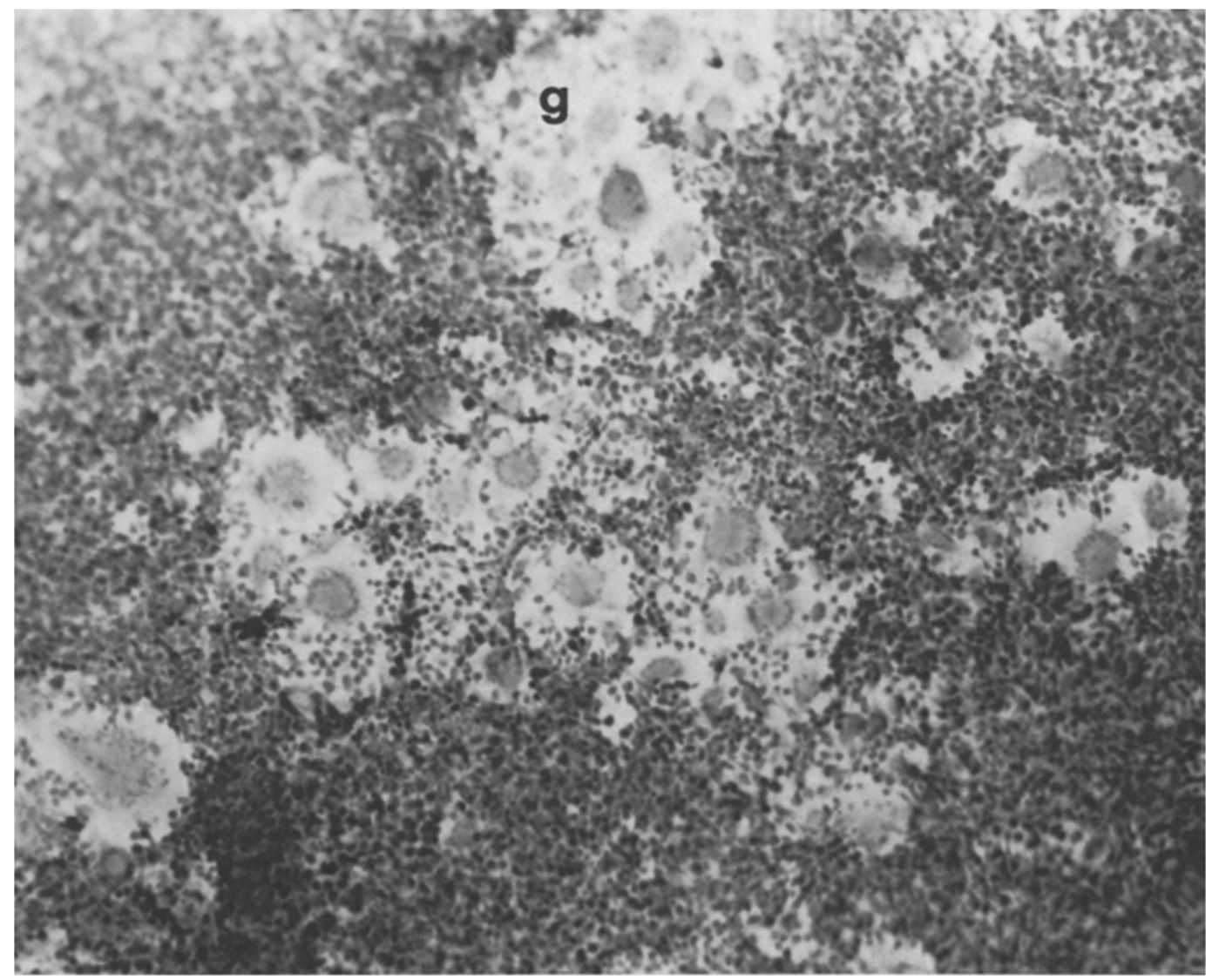

Fig. 5. Groups of numerous giant cells $(g)$ on the surface of the plastic implant within the monolayer of macrophages. Lens implant cytology technique, $\mathrm{H} \& \mathrm{E}$ stain, photomicrograph $\times 150$ 


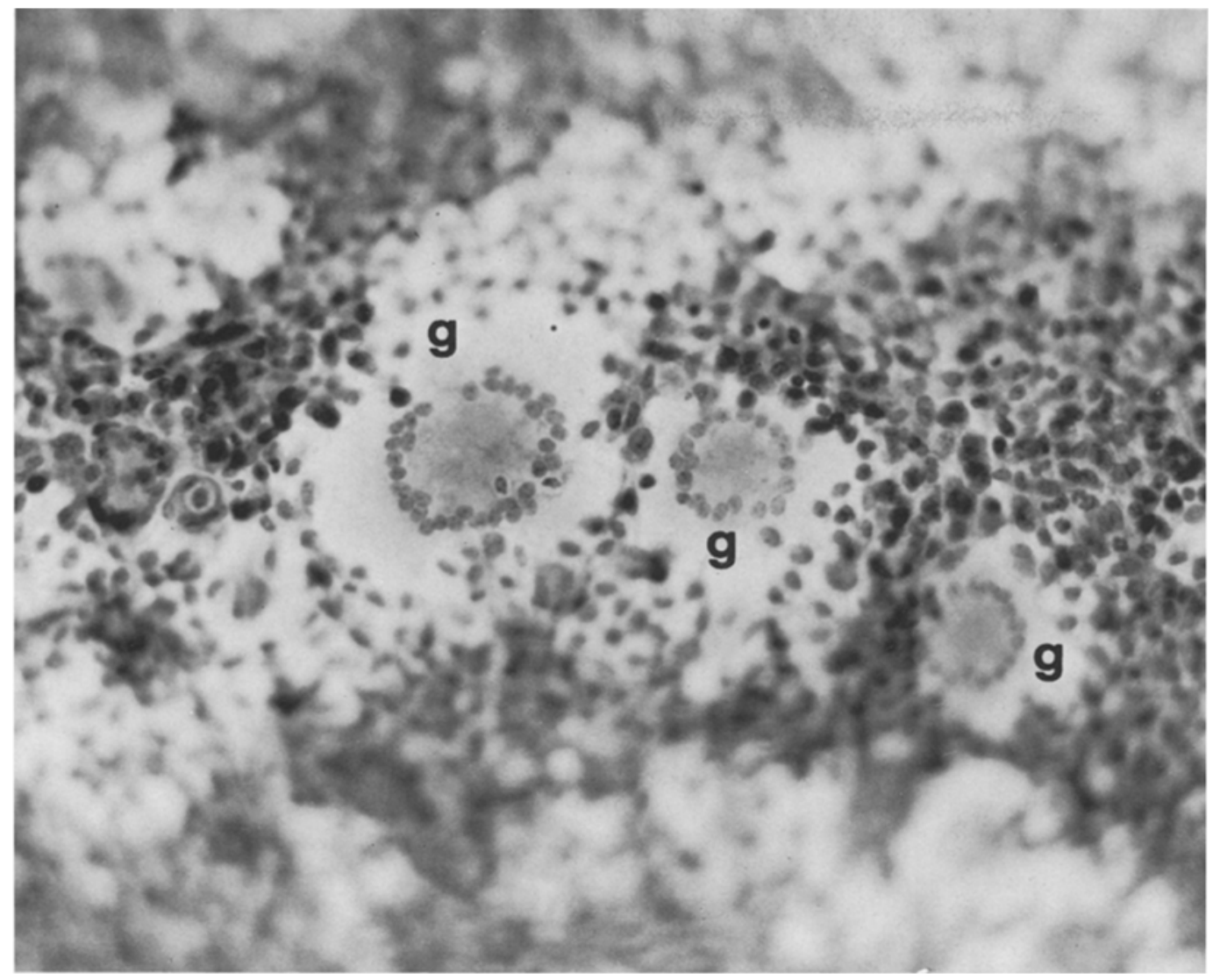

Fig. 6. Fully developed giant cells $(g)$ with a ring of nuclei, an eosinophilic central protoplasm, and a light protoplasmic halo on the surface of the plastic implat. The surrounding macrophages form a monolayer. Lens implant cytology technique, $\mathrm{H} \& \mathrm{E}$ stain, photomicrograph $\times 400$

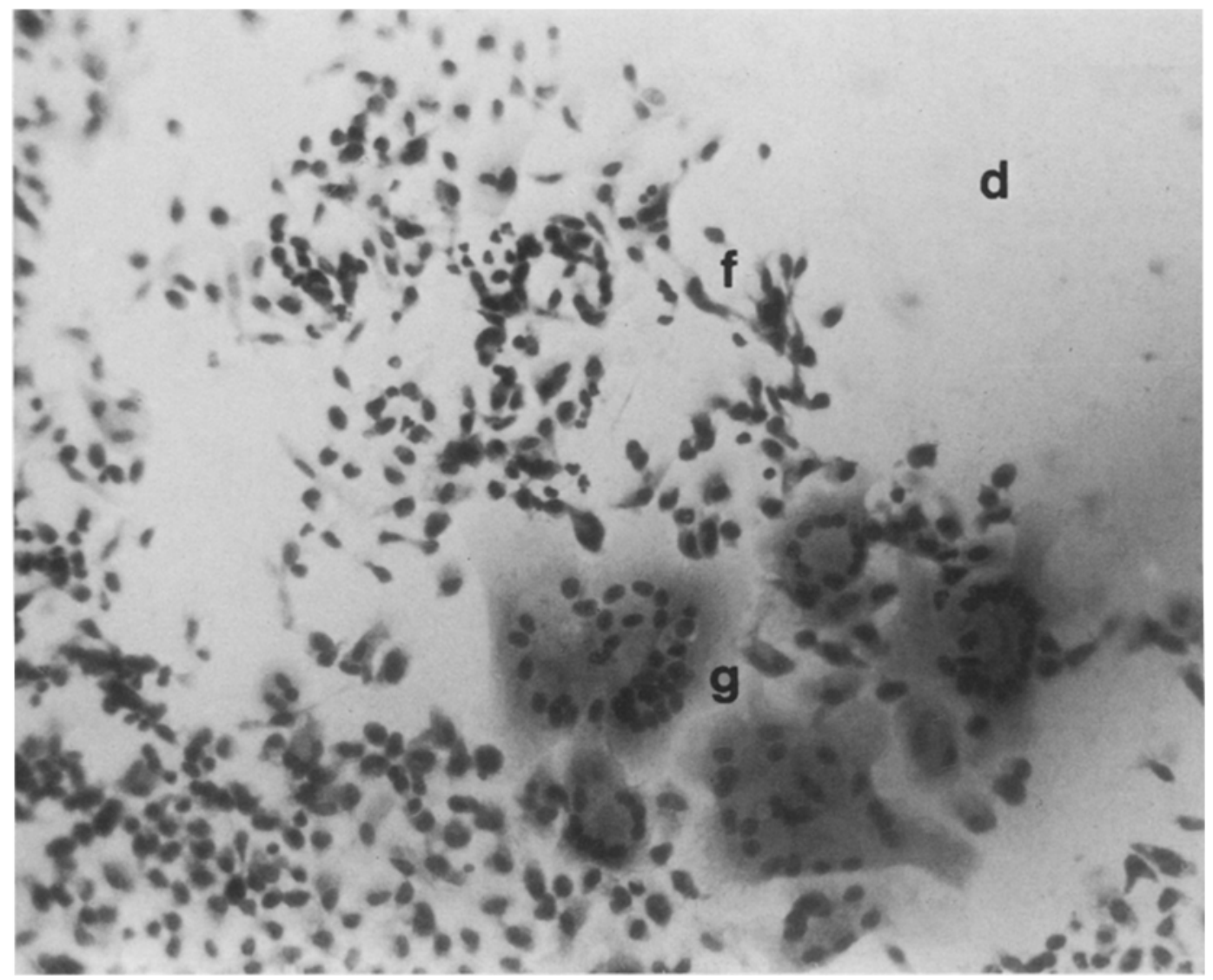

Fig. 7. Groups of fibroblastlike cells $(f)$ next to the defect $(d)$ in the cell layer on the plastic implant (compare Figs. 1 and 3 ). There are also some more or less fully developed giant cells $(g)$. Lens implant cytology technique, H \& E stain, photomicrograph $\times 400$ 


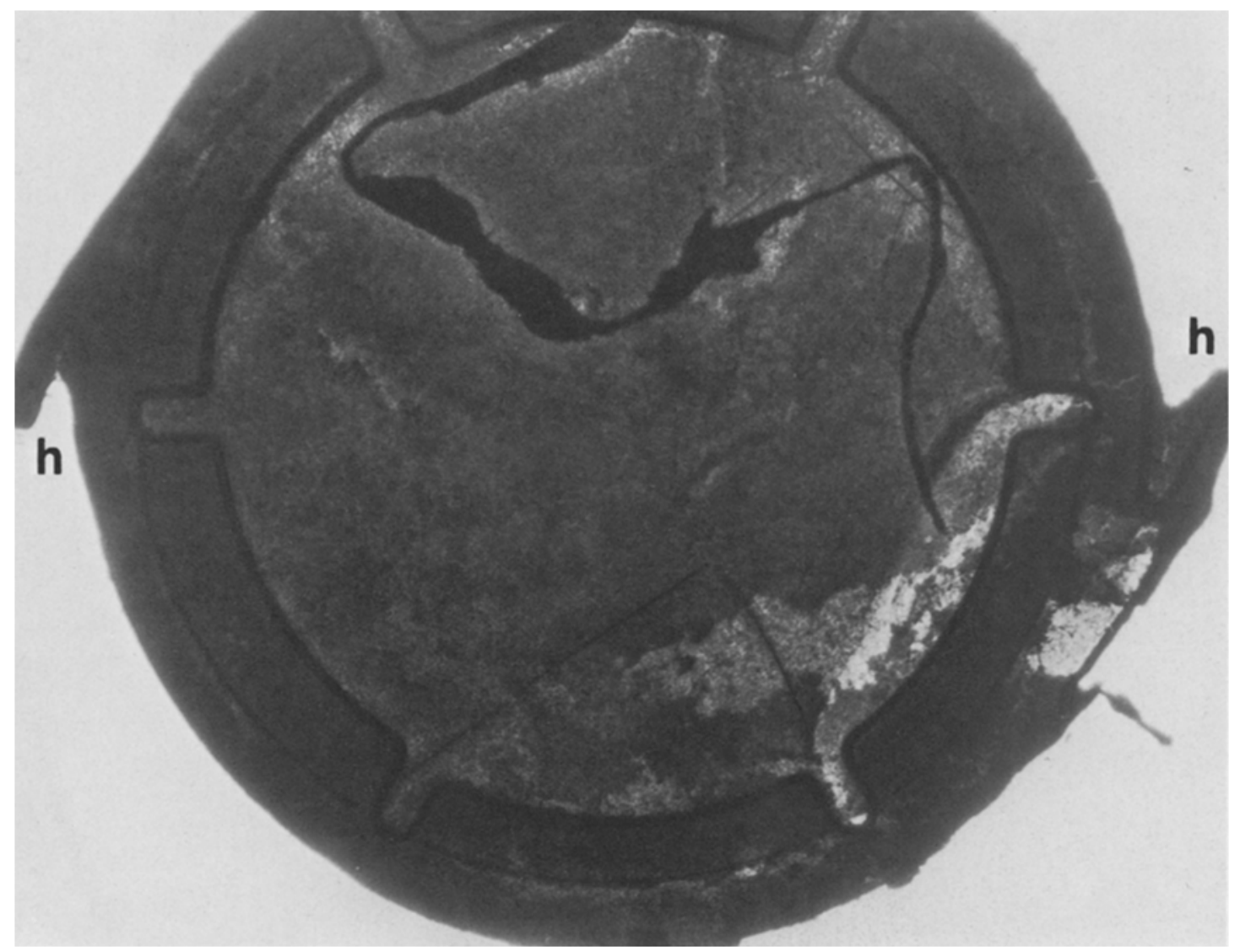

Fig. 8. Optic portion of a glass lens implant after 5 days in the peritoneal space of a mouse with a dense multilayer of macrophages all over its surface. The stumps of haptics $(h)$ are seen. A strand of densely accumulated macrophages hangs loose to the surface of the implant. Lens implant cytology technique, H \& E stain, photomicrograph $\times 25$

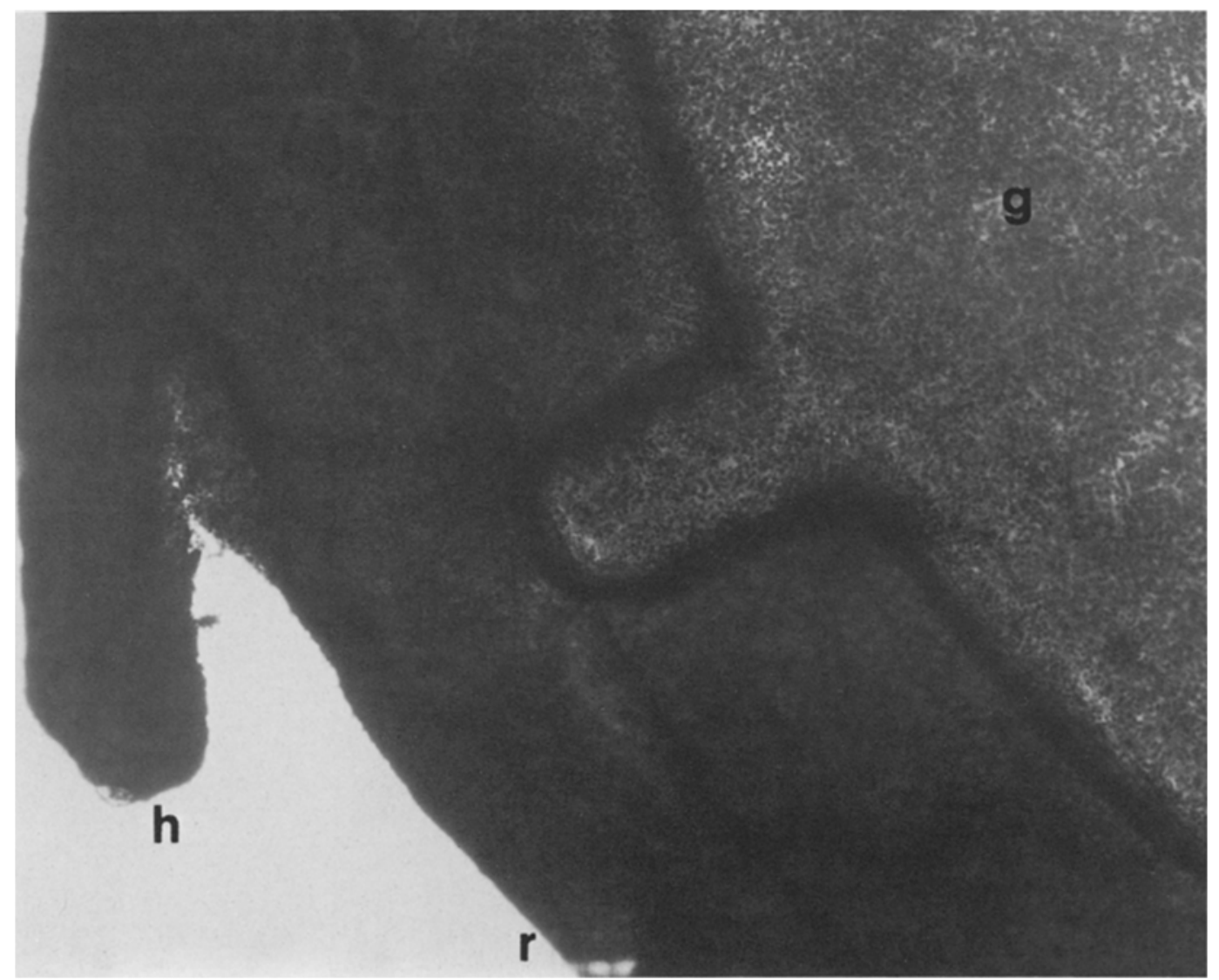

Fig. 9. Segment of the plastic rim of the glass implant. Macrophages cover the glass optics $(g)$, the rim $(r)$, and the stumps of the haptics $(h)$. They have also extended into the narrow cracks between glass and supporting rim. Lens implant cytology technique, $\mathrm{H} \& \mathrm{E}$ stain, photomicrograph $\times 90$ 


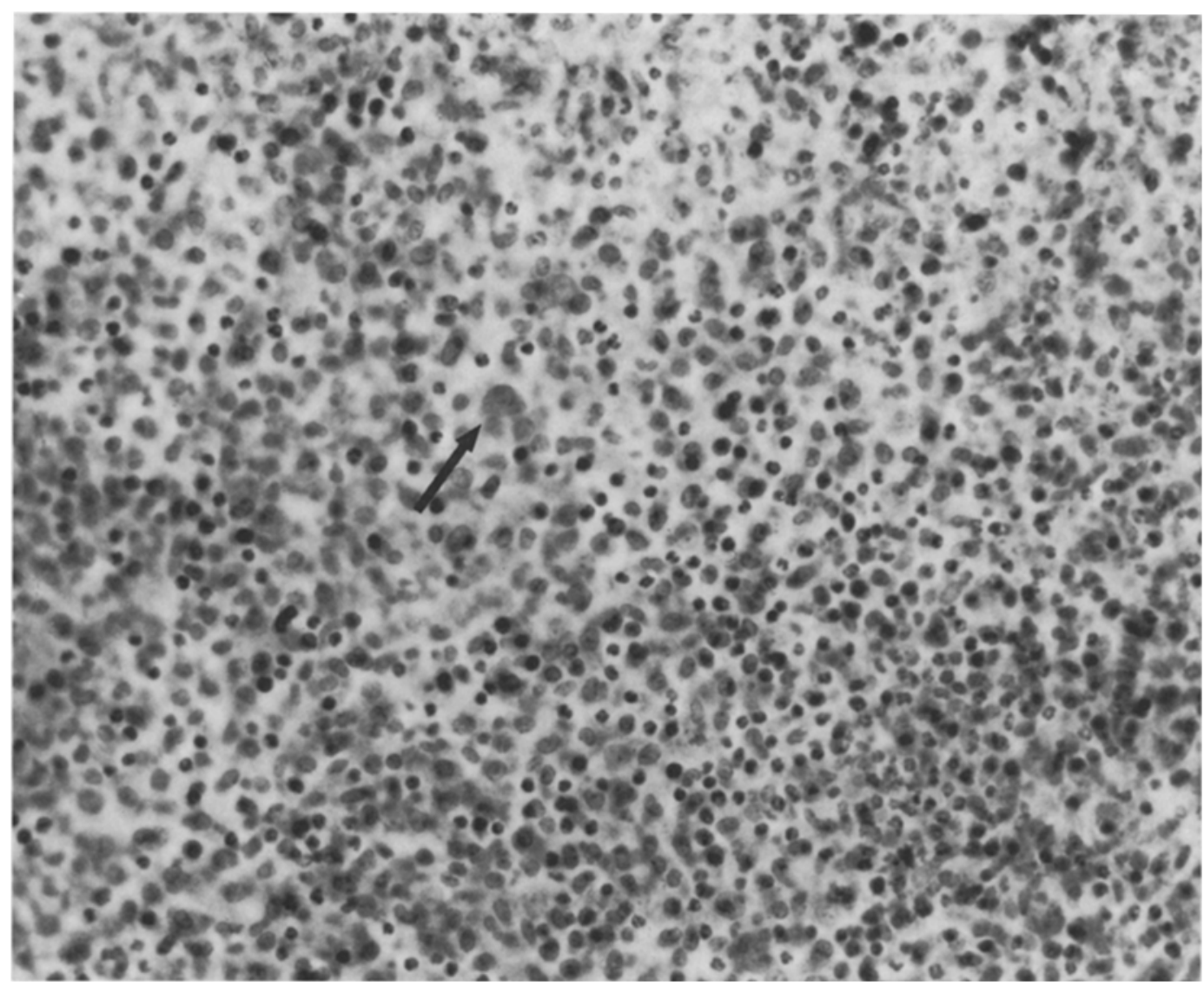

Fig. 10. High-power view of the macrophages on the surface of the glass implant. There are no giant cells and only very occasional macrophages have the appearance of epithelioid cells (arrow) with a larger nucleus and a more extentive protoplasm. Lens implant cytology technique, $\mathrm{H} \& \mathrm{E}$ stain, photomicrograph $\times 400$

tinucleated cells, as well as formation of an acellular capsule in the interspaces, was seen in tissue culture only when the number of macrophages was limited. There were occasional multinucleated cells, but the development of true giant cells on lens implants was not observed in tissue culture.

Macrophages are part of the so-called mononuclear phagocyte system. All macrophages are believed to originate in the bone marrow and become monocytes of the circulating blood. They leave the blood stream to become free macrophages of the tissues and fluids of the organism. The speedy supply of macrophages to the inner eye is limited due to the fact that they have to come from the capillary vessels of iris, ciliary body, retina, and optic nerve. The capillaries in these tissues are either thick-walled or separated from the inner eye by membranes. The abdominal space, in contrast, has in its peritoneum an extensive network of thin-walled vessels that can quickly supply great numbers of all kinds of inflammatory cells as a result of different types of irritation and inflammation. This fact explains the generous formation of reactive cellular membranes mainly composed of macrophages on the surface of the implants in the present experiments. These membranes are not only rich in cells, but they also contain much gluelike exudate that allows for firm fixation of the cells to the surface of these implants.

Lens implants in the peritoneal space of the mouse abdomen did not cause a severe reaction of any kind, and the animals did not obviously suffer from the presence of these implants. The implants did not cause a severe peritoneal inflammatory reaction with exudation, bleeding, or adhesions. The implants were found to be freely movable when the animals were killed 5 days after the implantation of the lenses. The adjacent peritoneum was involved with only a slight and localized nongranulomatous inflammatory reaction.

Most of the cells on the surface of the lens implants in the present experiments were typical mononuclear macrophages. The glass implant had attracted more macrophages than the polymethylmethacrylate implant in these single instances. Polymorphnuclear leukocytes were also attracted to both implants, but the glass implant exhibited fewer of these representatives of acute inflammation. Some of the macrophages attached to the implants were seen in different stages of developing into typical epithelioid cells, but this development was much more prominent on the plastic implant.

The presence of well-developed giant cells of relatively large size with up to 80 nuclei in the monolayer of macrophages on the surface of the abdominal plastic lens after a period of only 5 days was a surprise. Clinical studies had given us the impression that it takes much longer for these large reactive cells to develop. Study of the giant cells allowed for the recognition of different stages of their formation, and it could be concluded that they develop by protoplasmic fusion of macrophages. The arrangement of the nuclei in the form of perfect rings around the protoplasmatic centers of the giant cells has been observed before 
in the giant cells on the surface of implants removed from human eyes $[1,8]$. However, giant cells on human lens implants may also have the irregular arrangement of their nuclei all through the protoplasm that is typical for foreignbody giant cells' $[2,6]$. Alternatively, they may resemble typical Langhans' giant cells, with the nuclei lined up directly next to the outer protoplasmic border [5]. The fact that the plastic implant exhibited numerous giant cells, whereas the glass implant was without any giant cells, is remarkable. The glass implant had attracted more macrophages in comparison to the plastic implant - and these were accumulated in several layers - while the plastic implant only had a dense monolayer of these cells on most of its surface. The glass implant had attracted fewer PMNs, and its macrophages showed fewer signs of becoming sessile elements on its surface. It is obvious that the testing of greater numbers of different implants will be necessary before definite conclusions about these differences in the cell reactions can be made.

Experimental placement of intraocular lens implants in the peritoneal space of mice undoubtedly has excellent potential for the study of the stages of cytological development leading to the permanent separating membranes on the surface of such implants. This can also be used for routine testing of differences in the formation of these membranes on implants of different composition and shape. Peritoneal mouse macrophages are sufficiently similar to intraocular macrophages in man to make such testing practical in the search for implants that elicit the formation of the optimal separating membrane. We believe that the membranes on the surface of lens implants are beneficial. They are nature's way of adapting the foreign substance of lens implants to the inner eye. To be optically clear, membranes on lens implants have to be thin. They should contain only few inactive fibroblastlike cells (sessile macrophages) in a regular distribution. Giant cells of any kind in the membranes are indicators of cytological unrest, and these are therefore undesirable. Delicate planning and tissue engineering will be needed to develop the best possible membranes for our purposes. Up to the present time, the selections concerning the composition, shape, support, location, and placement technique for intraocular lens implants have been made mostly by courageous surgeons on the basis of instinct and clinical observation. We believe that the time has come for careful study of the involved reactive processes and the application of modern testing from the fields of cytology, histopathology, and immunology, for example, as well as from the bordering fields of mechanical, physiological, chemical, and optical engineering. This will take the fun out of the "operating by the seat of the pants" type of lens implant surgery, but at the same time it will allow this field to become a true science.

The investigation of the peritoneal space as an area for membrane formation on lens implants by macrophages may not necessarily be only an impractical step on our way toward understanding the cytological reactions on the surface of these lenses. The eye surgeon of the future will probably like to use a lens that is already covered with a fully developed reactive membrane of the patient's own cells for intraocular implantation to avoid the hazards of this reactive process in the delicate surroundings of the inner eye. One could thus easily envisage an implant being first introduced and suspended in the peritoneal space for a few weeks or months. This would then be removed and transferred into the eye, along with its living membrane, at the time of the cataract operation.

\section{References}

1. Wolter JR (1982) Cell life on the surface of lens implants. Graefe's Arch Clin Exp Ophthalmol 218:244-249

2. Wolter JR (1982) Foreign body giant cells on intraocular lens implants. Graefe's Arch Clin Exp Ophthalmol 219:103-111

3. Wolter JR (1982) Lens implant cytology. Ophthalmic Surg 13:939-942

4. Wolter JR (1983) Reactive membrane on lens implant: three months after implantation. Graefe's Arch Clin Exp Ophthalmol $220: 53-57$

5. Wolter JR (1983) Pseudophaco-anaphylactic endophthalmitis? Graefe's Arch Clin Exp Ophthalmol (in press)

6. Wolter JR, Felt DP (1982) Proliferation of fibroblast-like cells on failing intraocular lenses. Ophthalmic Surg 14:57-64

7. Wolter JR, Kunkel SL (1983) Adherence of mouse macrophages to plastic lens implants resulting in the formation of a cellular membrane. Ophthalmic Surg (in press)

8. Wolter JR, Lichter PR (1983) Fibroblastlike cells on intraocular lens implants: phagocytizing erythrocytes. $\mathrm{Br} \mathrm{J}$ Ophthalmol (in press)

Received April 15, 1983 